\title{
Tonic immobility in adult Colorado potato beetle, Leptinotarsa decemlineata (Coleoptera: Chrysomelidae) evoked by mechanical and optical stimuli
}

\author{
LuUle METSPALU ${ }^{*}$, Aare KUUSIK ${ }^{1}$, Külli HIIESAAR ${ }^{1}$ and Urmas TARTES ${ }^{2}$ \\ ${ }^{1}$ Institute of Plant Protection, Estonian Agricultural University, Kreutzwaldi 64, 51014 Tartu, Estonia \\ ${ }^{2}$ Institute of Zoology and Botany, Estonian Agricultural University, Riia 181, 51014 Tartu, Estonia
}

Key words. Tonic immobility, gas exchange, body movements, heartbeats, Colorado potato beetle, Leptinotarsa decemlineata

\begin{abstract}
Adults of Colorado potato beetle Leptinotarsa decemlineata are very active at room temperature, and their almost continuous struggling in the respirometer prevents the measurements of the patterns of gas exchange, body movements and heartbeat. The tonic immobility of beetles was evoked by light flashes and by shaking as external stimuli. The immediate reaction to these stimuli was the reflexive closing of the spiracles and the cessation of $\mathrm{CO}_{2}$ release for some minutes, which was followed by a large burst of this gas. The state of the evoked tonic immobility did not influence heartbeat and abdominal pulsations, but the periodically -occurring abdominal-thoracic pumping movements stopped for 2-5 minutes. During the periods of pumping ventilation the metabolic rate was increased about two times. The state of tonic immobility evoked by light flashes lasted 2-6 minutes, but when shaking was applied as a stimulus complete immobility was about two times longer.
\end{abstract}

\section{INTRODUCTION}

A respiratory characteristic which has often been used is the cyclicity of gas exchange; i.e., the mode of $\mathrm{CO}_{2}$ emission from the tracheae. Many insects in adult, pupal and even in larval stages display discontinuous gas exchange cycles (DGCs) (Kestler, 1984; Lighton, 1994; Miller, 1974, 1981; Slama, 1988; Slama \& Coquillaud, 1992; Snyder et al., 1995; Wasserthal, 1996; for reviews).

For the determination of metabolic rates and respiratory patterns the individual insect must be motionless. Many adult insects, including the Colorado potato beetle Leptinotarsa decemlineata (Say), are very active at room temperature, and it is often a very complicated task to force them to stop struggling and stay motionless in an insect chamber of a respirometer, and the periods of immobility are commonly too short for studying respiration patterns.

Several methods have been proposed to immobilize insects. The use of the anaesthetic enflurane has been recommended to ensure immobility in ants and other small active insects during the determination of standard metabolic rates (Holm-Jensen et al., 1980), but the anaesthetic cannot be used for quantifying the respiration pattern (Duncan \& Newton, 2000).

Decapitation has been demonstrated as a useful means of immobilizing ants for the measurement of the resting gas exchange, while movement is minimal and ventilation (i.e., the DGCs) is much more regular and stereotyped (Lighton, 1992; Quinlan \& Lighton, 1999).

Many insects, especially coleopterous species, respond to a sudden and brief mechanical or optical stimulus by abruptly reaching a state of more or less complete tonic immobility, lasting from a few seconds to several hours. Shaking of the food plant and loss of tarsal contact, but also illumination, may act as stimuli for immobility. If the foothold is released and the insect falls to the ground, the immobility is often called thanatosis or death feigning. A protective pose while retaining its foothold has been termed as catalepsy or tonic immobility ("freezing"), and this term has been used to cover both types of responses, because it describes the general condition (see Richards, 1953) of the insect.

Our idea was to achieve the immobility of Colorado potato beetles for a period of time by evoking freezing by mechanical or optical stimuli. To our knowledge the metabolic rates and respiratory patterns during "freezing" have so far not been studied in insects, or at least not in Coleoptera.

The goal of the present study was to test optical stimuli, light flashes, and mechanical stimuli, shaking, to estimate their suitability for the evocation of tonic immobility in adult Colorado potato beetles. Another goal was to characterize the metabolic rates and respiratory patterns in summer beetles during the induced state of freezing. The possible adaptation of beetles to the applied stimuli was also studied.

\section{MATERIAL AND METHODS}

Adult Colorado potato beetles of first generation were collected in July and August from potato fields near Tartu (Estonia) and then kept in a laboratory at room temperature. For experiments 35 beetles of both sexes, weighing 130-160 mg, were used.

The electrolytic microrespirometer we used was described in detail earlier (Kuusik et al., 1996; Tartes et al., 1999). An infrared gas analyzer (Infralyt-4, Dessau) was exploited for recording the $\mathrm{CO}_{2}$-emission.

Eppendorf conical test tubes (volume of $1.5 \mathrm{ml}$ ) were used as insect chambers. In the conical part of the test tube the beetle was in a motionless posture, and only the respirograms showed whether it was struggling or motionless. Cylindrical tubes

\footnotetext{
* Corresponding author. E-mail: mluule@eau.ee
} 


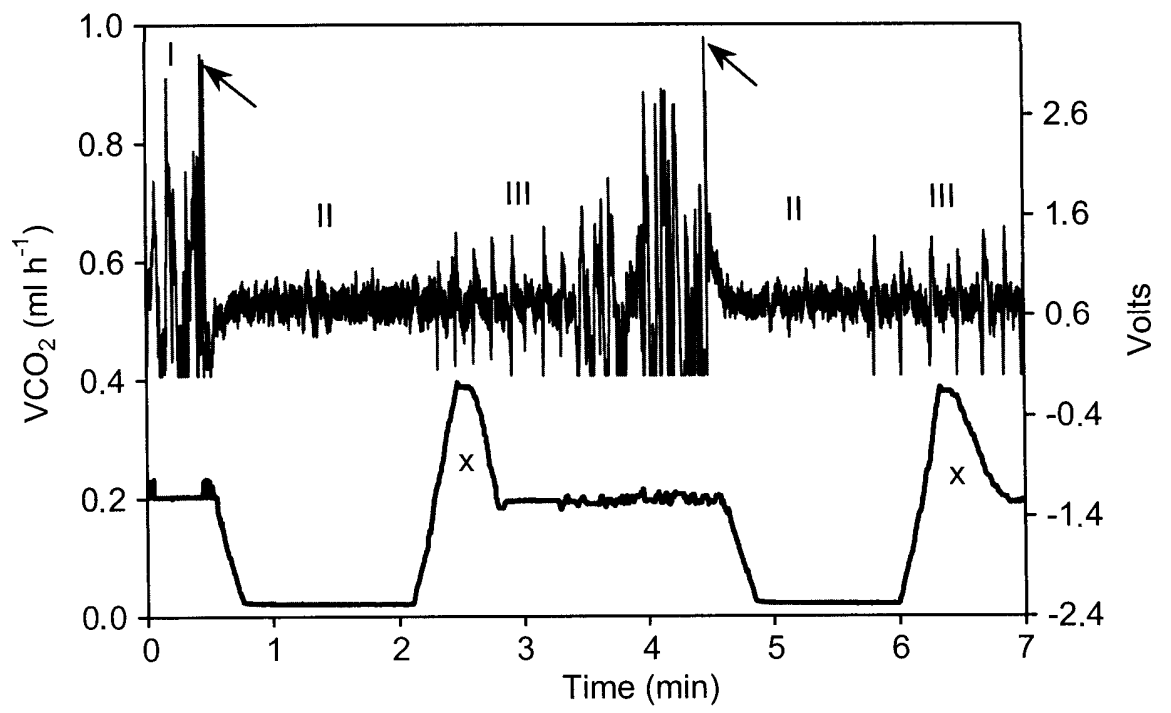

Fig. 1. Simultaneous recordings of an infrared gas analyser (lower trace, $\mathrm{VCO}_{2}$ ) and infrared sensors (upper trace, Volts) showing the influence of light flashes (arrows) on the $\mathrm{CO}_{2}$ release and abdominal movements in an adult Colorado potato beetle. $\mathrm{x}-\mathrm{CO}_{2}$ burst, I - body movements of struggling beetle before the light flash; II - heartbeats modulated by abdominal pulsations; III strokes of pumping movements superimposed on heartbeats and abdominal pulsations.

(volume of $5 \mathrm{ml}$ ) were another type of insect chamber, where the fixed beetle laid on its back for visual observation of the posture and movements of its legs. Insect chambers of both types were connected either to the respirometer or infrared gas analyzer by means of rubber tubing.

On the graphs are indicated the units " $\mathrm{VO}_{2}\left(\mathrm{ml} \mathrm{h}^{-1}\right)$ ", which corresponds to the rate of oxygen production by electrolysis. The mean metabolic rate can be calculated by averaging data over a shorter or longer period (see Tartes et al., 1999). During the baselines of the recording (e.g., between two peaks) the units $\mathrm{VO}_{2}\left(\mathrm{ml} \mathrm{h}^{-1}\right)$ correspond roughly to the metabolic rate of the insect.

The respirometric device was combined with an infrared (IR) optical system using IR-emitting diodes (TSA6203) and IRsensor diodes (BP104), which were placed on the sides of the insect chamber (for details about this IR optical device see Hetz, 1994; Wasserthal, 1996; Kuusik et al., 2001; Metspalu et al., 2001). All measurements were performed in a thermostat at $22 \pm$ $0.5^{\circ} \mathrm{C}$, while visual observations were made at room temperature, between 20 and $24^{\circ} \mathrm{C}$.

The analogue-to-digital conversion of the measuring apparatus was made using a data acquisition board DAS 1601 (Keithley-Metrabyte) with TestPoint software (Capital Equipment Corp., Billerica, MA, U.S.A.). The sampling rate was 10 $\mathrm{Hz}$.

The graphs are the recordings of single beetles; however, the patterns shown are characteristic of all of the beetles examined.

\section{RESULTS}

\section{Struggling and pumping ventilation}

At room temperature the adult Colorado potato beetles laying on their backs in the insect chambers struggled almost continuously. The locomotion of the beetles in the chamber was prevented mechanically and the movements of their legs were the only external signs of struggling. The respirometric and infrared sensor indicated the patterns due to struggling (Fig. 1 and 2).

The external stimuli, light flashes or shaking, immediately terminated the struggling, while the legs stayed in a motionless posture. The beetles displayed freezing or death feigning as a result of these stimuli, and a clear pattern of heartbeats appeared on optical recordings (Fig. 1 and 2). The complete immobility lasted 1-2 minutes, followed by a period of a series of regular pumping movements involving both abdominal and thoracic segments. The state of tonic immobility, which commonly lasted 3-12 minutes, ended abruptly and struggling began. The following light flashes evoked the same events (Fig. 1).

There were beetles which did not struggle in the insect chamber and being externally motionless, they exhibited continuous pumping movements (Fig. 3). Light flashes instantly terminated the abdominal-thoracic pumping, and the beetles displayed complete immobility until these movements started again (Fig. 4). The frequency of pumping movements varied within a great range $(0.02-$ $0.15 \mathrm{~Hz}$ ).

The metabolic rate during the pumping movements was about twice as high $\left(0.8-1.0 \mathrm{ml} \mathrm{O}_{2} \mathrm{~g}^{-1} \mathrm{~h}^{-1}\right)$ as that during periods when these movements were absent $(0.4-0.5 \mathrm{ml}$ $\left.\mathrm{O}_{2} \mathrm{~g}^{-1} h^{-1}\right)$.

\section{Abdominal pulsations}

All of the beetles we studied which were in a state of tonic immobility showed very weak rhythmic abdominal movements, which were imperceptible by visual observations, even if made under a stereomicroscope. Nevertheless, on the respirograms regular signals of $0.1-0.5 \mathrm{~Hz}$ (Fig. 5) were observed. We regard these weak abdominal movements as abdominal pulsations, which also persisted during the muscular ventilation. On the respirograms the abdominal pulsations were easily distinguishable from the muscular ventilation because of their different amplitudes and frequencies (Fig. 5). 


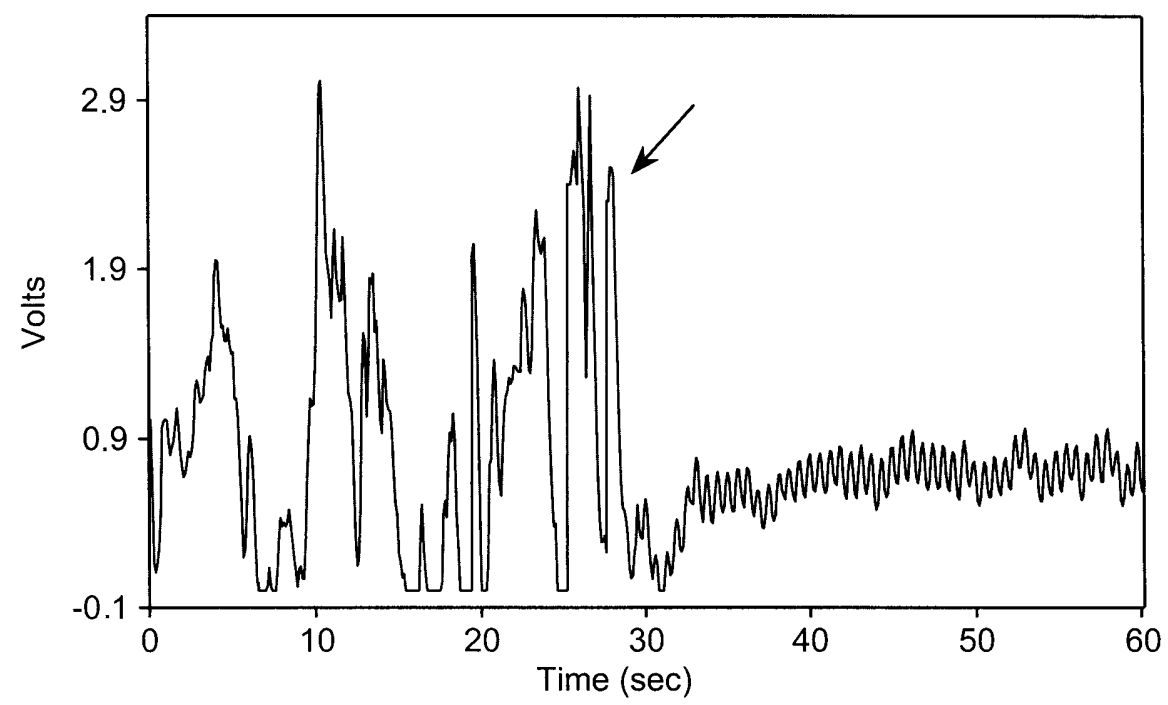

Fig. 2. A detail of Fig. 1. High peaks before a light flash (arrow) are due to struggling; regular peaks after the ligh flash are heartbeats modulated by abdominal pulsations.

\section{Gas exchange}

After the light flashes or shaking the $\mathrm{CO}_{2}$ release declined to a level of zero and stayed there for 1.5-4 minutes, followed by a large burst of gas (Fig. 1). Sometimes the pumping movements were initiated with the burst, but sometimes the pumping movements followed only after the burst.

A characteristic event was an abrupt upward peak, occurring 30-50 seconds after light flash and about 1-2 minutes before a $\mathrm{CO}_{2}$ burst. It seems likely, as determined by the respirograms, that the beetles responded to the external stimuli by at once closing the spiracles tightly for $30-50$ seconds, followed by air intake into the tracheae. Thereafter, a period followed during which oxygen was consumed, but $\mathrm{CO}_{2}$ was not released (Fig. 1). When the mechanical stimulus was applied during the $\mathrm{CO}_{2}$ burst, the burst was interrupted and $\mathrm{CO}_{2}$ emission declined to a level of zero for 2-3 minutes.

\section{Heartbeat}

The mechanical stimuli did not change the frequency and amplitude of the heartbeats as determined by infrared sensor recordings. The pattern of heartbeat was modulated by abdominal pulsations, while the ventilatory movements caused the higher peaks superimposed on the heartbeats (Fig. 5). Thus the state of freezing influenced neither the heartbeats nor the abdominal pulsations.

The visual observations of beetles after removing the elytra and wings showed only the forward heartbeats. Simultaneous recordings with two IR-sensor diodes at the second and fifth abdominal tergites also showed only forward directed heartbeats.

\section{Adaptation}

If an external stimulus, light flashes or shaking was applied in intervals of 5-8 minutes during 2 hours of experiments, then no signs of adaptation to these stimuli

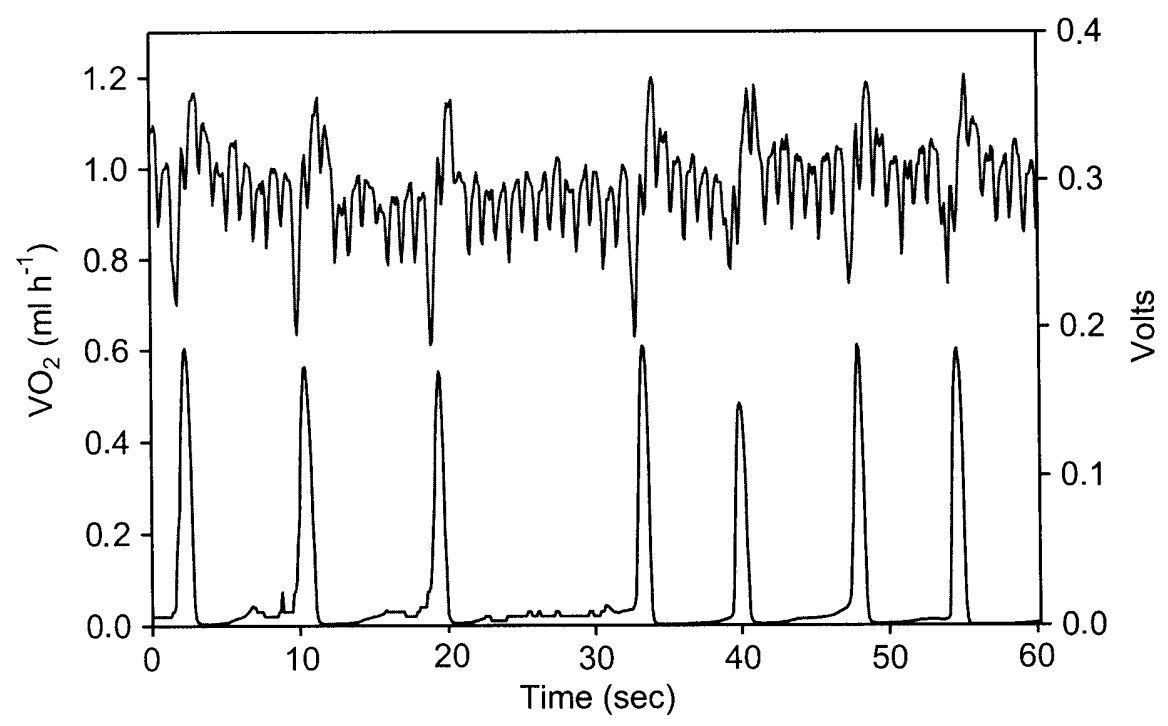

Fig. 3. A typical pattern of pumping movements in adult Colorado potato beetle by using an electrolytic respirometer (lower trace, left scale). On the simultaneous infrared sensor recording (upper trace, Volts) the heartbeats are superimposed on the signals of body movements. 


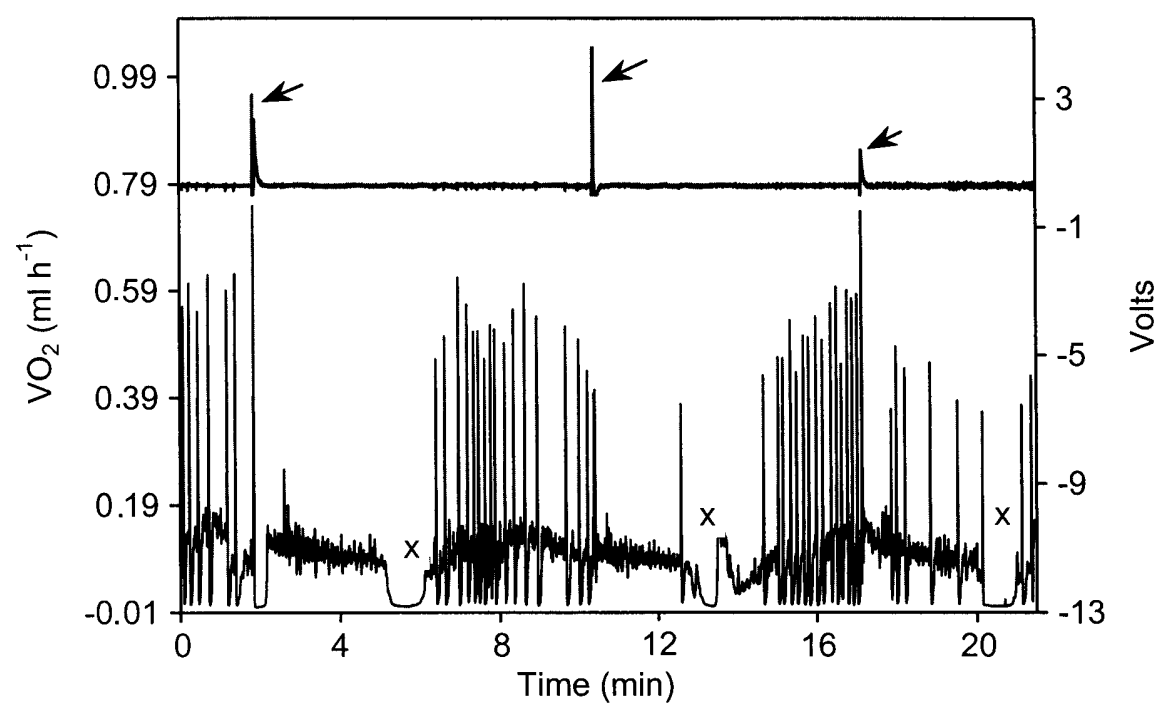

Fig. 4. The influence of light flashes on the restrained adult Colorado potato beetle displaying pumping movements. Arrows on the upper trace (IR-sensor recording, Volts) indicate light flashes. Higher spikes on the lower trace (respirogram, left scale) are pumping movements; the lower and more frequent spikes are due to abdominal pulsations. $\mathrm{x}-\mathrm{CO}_{2}$ bursts.

were observed. However, there were individuals which adapted more rapidly to light flashes than others. The strokes of abdominal pumping, which appeared before a $\mathrm{CO}_{2}$ burst after the third subsequent light flash, served as a sign of rapid adaptation (Fig. 4).

\section{DISCUSSION}

Light flashes and shaking induced a state of tonic immobility or freezing, which lasted 3-12 minutes in struggling adult Colorado potato beetles. During the first phase of thanatosis only heartbeats and abdominal pulsations were represented on the recordings. In the next phase the regular muscular ventilation occurred until the "awakening" of beetles from freezing and the beginning of struggling.
An interesting finding was an abrupt cessation of $\mathrm{CO}_{2}$ emission immediately after the light flash or shaking. The stimuli were applied during the $\mathrm{CO}_{2}$ burst, the latter was interrupted. We suggest that the stimuli resulted in the tight closing of the spiracles for some time.

During the state of tonic immobility the Colorado potato beetles exhibited very weak, externally imperceptible, abdominal movements or abdominal pulsations. In active beetles the signals of abdominal pulsations are usually mixed with other signals on the recordings and, therefore, may easily be undetected. Different frequencies and amplitudes of heartbeats, abdominal pumping and abdominal pulsations allowed us to distinguish between these different events during the state of immobility.

In our opinion the abdominal pulsations found in adults of Colorado potato beetle are similar to the "extracardiac

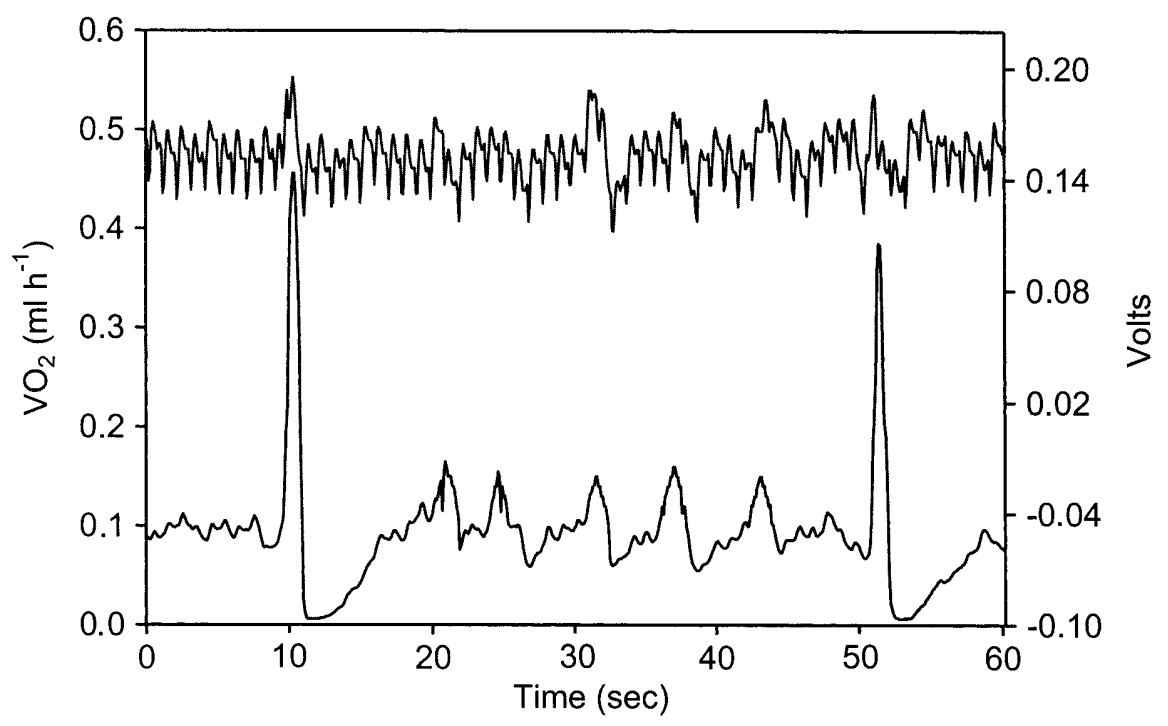

Fig. 5. A respirogram from an adult Colorado potato beetle (lower trace, left scale), where two higher peaks mark the abdominalthoracic pumping movements, while between them the lower 4-5 peaks are due to abdominal pulsations. The simultaneous optical recording (upper trace, Volts) are heartbeats modulated by pumping movements and abdominal pulsations. 
haemocoelic pressure pulses" discovered by Slama (1976) and described later in insects of several taxonomic groups and various developmental stages (see Slama, 1984). The autonomic nervous system (coelopulse) located within thoracic ganglia regulates the extracardiac pressure pulses, and these pulses play a role in respiration and haemolymph circulation (Slama, 1994, 1999, 2000).

These haemocoelic pressure pulses were recorded on the insect body by means of electronic transducers or direct hydraulic transducers (Slama, 1988). The infraredsensor method which we used allowed recording of both the rhythm of abdominal pumping and the weak abdominal pulsations of the Colorado potato beetles.

We conclude from our results that the evoking of tonic immobility by means of external mechanical or optical stimuli may be used to restrain the adults of Colorado potato beetle for a sufficient time in order to measure the metabolic rates, rhythms or pumping movements and abdominal pulsations, as well as gas exchange patterns.

ACKNOWLEDGEMENTS. This research was supported by the Estonian Science Foundation grants No. 3535, No. 4993 and No. 4073.

\section{REFERENCES}

DunCan F.D. \& NEWTON R.D. 2000: The use of the anaesthetic enflurane, for determination of metabolic rates and respiratory parameters in insects, using the ant, Camponotus maculatus (Fabricius) as the model. J. Insect Physiol. 46: 1529-1534.

HETz S.K. 1994: Untersuchungen zu Atmung, Kreislauf und Säure-Basen-Regulation an Puppen der tropischen Schmetterlingsgattungen Ornithoptera, Troides und Attacus. Dissertation, University Erlangen-Nürnberg, Germany, 190 pp.

Holm-Jensen I., Jensen T.F. \& Nielsen M.G. 1980: The influence of temperature upon the rate of $\mathrm{CO}_{2}$ production in enflurane anaesthetized worker ants of Formica rufa L. Ins. Sociaux. 27: 180-185.

KestLer P. 1984: Respiration and respiratory water loss. In Hoffmann K.H. (ed.): Environmental Physiology and Biochemistry of Insects. Springer, Berlin, pp. 137-183.

Kuusik A., Harak M., Hitesaar K., Metspalu L. \& Tartes U. 1996: Different types of external gas exchange found in pupae of greater wax moth Galleria mellonella (Lepidoptera: Pyralidae). Eur. J. Entomol. 93: 23-25.

Kưuik A., Tartes U., Vanatoa A., Hitesaar K. \& Metspalu L. 2001: Body movements and their role as triggers of heartbeats in pupae of the Colorado potato beetle Leptinotarsa decemlineata. Physiol. Entomol. 26: 158-164.
Lighton J.R.B. 1992: Direct measurement of mass loss during discontinuous ventilation in two species of ants. J. Exp. Biol. 173: 289-293.

Lighton J.R.B. 1994: Discontinuous ventilation of terrestrial insects. Physiol. Zool. 67: 142-162.

Metspalu L., Kuusik A., Hiesaar K., Jöudu J., Tartes U. \& HARAK M. 2001: Simultaneous recording of gas exchange cyclicity, body movements and heartbeats in pupae of Leptinotarsa decemlineata Say made by infrared optical method. Norw. J. Entomol. 48: 91-96.

Miller P.L. 1974: Respiration - aerial gas transport. In: Rockstein M. (ed.): The Physiology of Insecta. Academic Press, New York, San Francisco, London, 6: 345-402.

MiLLER P.L. 1981: Ventilation in active and inactive insects. In: Herreid C.F. \& Fourtner C.R. (eds): Locomotion and Energetics in Arthropods. Plenum Press, New York, pp. 367-390.

QUINLAN M.C. \& LiGirton J.R.B. 1999: Respiratory physiology and water relations of three species of Pogonomyrmex harvester ants (Hymenoptera: Formicidae). Physiol. Entomol. 24: 293-302.

RICHARDS K. 1953: Reflex activity and ganglion function. In: Roeder K.D. (ed.): Insect Physiology. John Wiley, New York, Chapman Hall, London, pp. 463-487.

SLAMA K. 1976: Insect haemolymph pressure and its determination. Acta Entomol. Bohemoslov. 73: 65-75.

SLAMA K. 1984: Recording of haemolymph pressure pulsations from the insect body surface. J. Comp. Physiol. (B) 154: 635-643.

Slama K. 1988: A new look at insect respiration. Biol. Bull. Mar. Biol. Lab. 175: 289-300.

Slama K. \& Coquillaud M.-S. 1992: Homeostatic control of respiratory metabolism in beetles. J. Insect Physiol. 38: 783-791.

SLAMA K. 1994: Regulation of respiratory acidemia by the autonomic nervous system (Coelopulse) in insects and ticks. Physiol. Zool. 67: 163-174.

Slama K. 1999: Active regulation of insect respiration. Ann. Entomol. Soc. Am. 92: 916-929.

Slama K. 2000: Extracardiac versus cardiac haemocoelic pulsation in pupae of the mealworm (Tenebrio molitor L.). $J$. Insect Physiol. 46: 977-992.

Snyder G.K., Sheafor B., Scholnick D. \& Farrelly C. 1995: Gas exchange in the insect tracheal system. J. Theor. Biol. 172: 199-207.

Tartes U., KuUsiK A. \& Vanatoa A. 1999: Diversity in gas exchange and muscular activity patterns in insect studied by respirometer-actograph. Physiol. Entomol. 24: 150-157.

WASSERTHAL L.T. 1996: Interaction of circulation and tracheal ventilation in holometabolous insects. Adv. Insect Physiol. 26: 297-351.

Received November 9, 2001; revised February 28, 2002; accepted April 29, 2002 